\title{
Modelo de Gestão de colaboração com Fornecedores Estudo de caso aplicado na Montadora
}

\author{
Claudio Cassiano, Roberto Moreira, Ugo Ibusuki \\ Mercedes-Benz do Brasil Ltda. \\ Av.Alfred Jurzykowski, 562, São Bernardo do Campo - SP 09680-900 \\ E-mail: claudio.r.cassiano@ daimler.com
}

\section{RESUMO}

O setor automotivo brasileiro tem feito grandes progressos como uma região de produção e vendas de veículos, mas é evidente o enfraquecimento da base industrial local, principalmente de autopeças resultante do aspecto da forte concorrência de produtos importados, que chegou a quase $29 \%$ do total das vendas locais (Sindipeças, 2011).

A nova política industrial (INOVAR-AUTO) aumenta as chances para o setor automotivo brasileiro contornar esta situação através de benefícios fiscais para a atividade de desenvolvimento de fornecedores onde até $50 \%$ das despesas com desenvolvimento de fornecedores de uma montadora poderá ser creditado através do desconto de IPI.

Este estudo analisou o modelo de Gestão Colaborativa de uma montadora de veículos junto a seus fornecedores através de um projeto de melhoria contínua desenvolvido por um time permanente de "kaizen" utilizando as ferramentas de "lean manufacturing" e replicando a vários outros fornecedores num modelo de inovação aberta. A inovação aberta tem se tornado um conceito efetivo para prover a busca de recursos externos por meio da colaboração de diversos atores na cadeia de valor para a busca de novos conhecimentos e tecnologias (Chesbrough, 2003).

O projeto desenvolvido num fornecedor de peças fundidas e replicado a outros cinco fornecedores trouxe um ganho médio através da redução do tempo de processamento da ordem de $30 \%$. Porém, o principal ganho deste projeto, foi a aproximação na relação de colaboração entre montadora e fornecedor que mostrou ganhos superiores ao antigo modelo de negociação e atrito onde o mais forte, no caso a montadora, cria um ambiente de pressão aos seus fornecedores para redução de custos, porém muitas vezes gerando redução de margem de lucro, consequente perda na capacidade de investimento e perda de competitividade. 


\section{INTRODUÇÃO}

A indústria automobilística brasileira está crescendo. As vendas do mercado interno atingiram 3,63 milhões de veículos em 2011, de acordo com o Anuário Automotivo do Brasil (ANFAVEA, 2011) impulsionando o Brasil à quarta posição no mundo atrás da China, EUA e Japão, mas à frente da Alemanha, França e Coréia. A expectativa da indústria é que as vendas atinjam 4,5 milhões de veículos em 2015 e mais de 6 milhões em 2025, com grandes investimentos já anunciados por fabricantes de automóveis em mais de \$30 bilhões até 2015 . Em 2011, a indústria automobilística representou 18,2\% do total do Produto Interno Bruto Industrial e 4,2\% do PIB total brasileiro.

O Brasil tem feito grandes progressos como fabricante de veículos e região de vendas, mas seria negligente ao ignorar o enfraquecimento da base industrial local de automóveis e autopeças, resultantes de aspectos cambiais e forte concorrência de produtos importados, que alcançaram 850 mil veículos em 2011, representando quase $25 \%$ do total das vendas domésticas. Nos últimos cinco anos tem havido um forte aumento no déficit da balança comercial no setor de autopeças e os carros fabricados aqui contendo alto índice de conteúdo importado (figura 1).

Figura 1: Balança Comercial Indústria Automotiva e Auto Peças
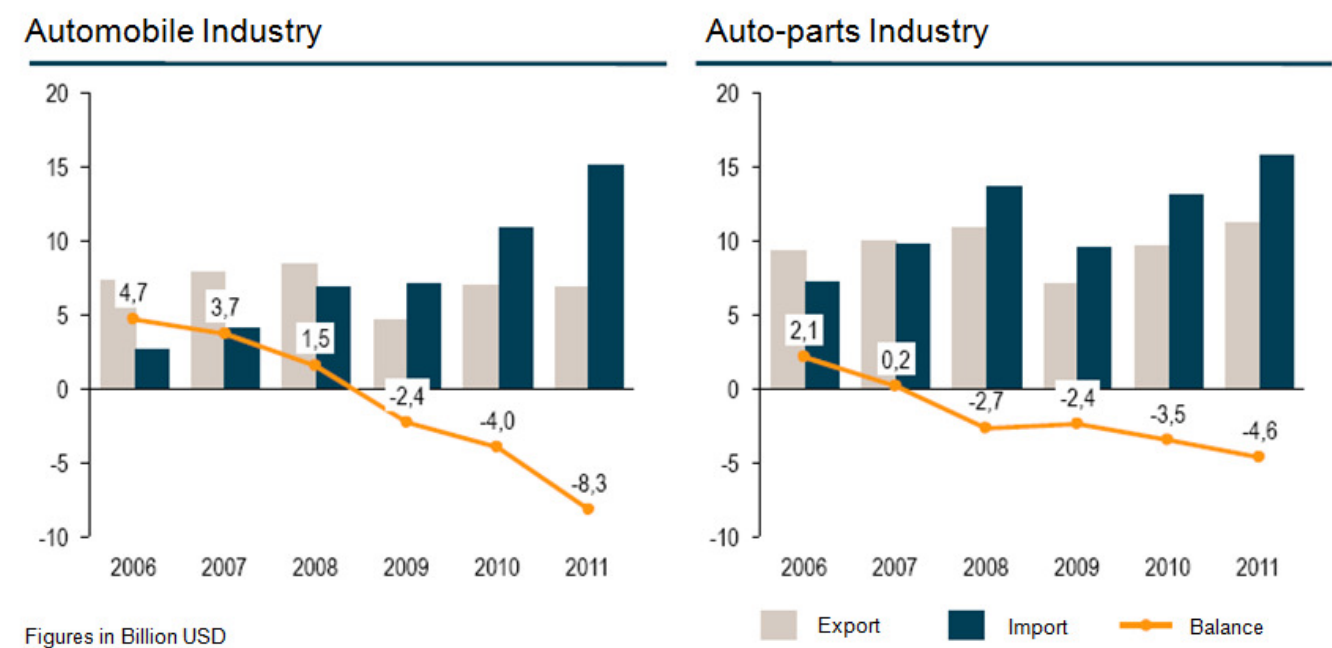

Fonte: ANFAVEA (2011) e Sindipecas (2011)

Este ponto claramente dá origem à questão da competitividade na cadeia produtiva instalada no país, cuja capacidade de sobreviver no futuro próximo está em sérias dúvidas, devido ao aumento contínuo no mercado dos importados (Sindipeças, 2011). Este não é um problema menor, uma vez que afeta o futuro da indústria e dos produtos que serão vendidos no país, além de interferir fortemente na capacidade local para projetar peças, sistemas e produtos finais. 
A fim de resolver este problema, o governo lançou em agosto de 2011 o "Plano Brasil Maior" (PBM), para melhorar a competitividade da indústria brasileira. A Nova Política Industrial Automotivo (INOVAR-AUTO), específica para a indústria automobilística brasileira, faz parte de um novo plano, e tem três objetivos principais: aumentar o estímulo ao investimento e inovação, proteção da indústria e do mercado interno.

O setor automotivo está estabelecido no Brasil desde 1950, desde então tem sido parte de várias políticas industriais relacionadas com o comércio, emprego e redução de impostos para apoiar o seu desenvolvimento (Arbix e Zilbovicius, 1997). A principal diferença do INOVAR-AUTO é que, pela primeira vez, a inovação é posicionada como um dos principais objetivos da política industrial automotiva.

Este trabalho analisa o modelo de Gestão Colaborativa da seguinte forma: Breve introdução do tema e objetivo desta pesquisa. Parte 1, análise da indústria automobilística brasileira e sua política de governo INOVAR-). Parte 2, metodologia do estudo, inovação aberta e a aplicação do Lean Manufacturing na inovação aberta e análise do estudo de caso. Parte 3 , está relacionada com a síntese da análise e conclusão desta pesquisa

\section{ANÁLISE DA INDÚSTRIA AUTOMOTIVA BRASILEIRA}

\subsection{Situação Atual da Indústria Automotiva e de Auto Peças Brasileira}

A indústria automobilística brasileira é composta de 18 fabricantes (dos quais 13 são fabricantes de automóveis de passageiros) e 37 plantas (dos quais 15 estão na região de São Paulo), com uma capacidade de produção total de 4,3 milhões de unidades (estatística 2011) e vendas mercado interno com cerca de 3,6 milhões de unidades (2011). A indústria é responsável por quase 400 mil empregados diretos (dos quais 150 mil na indústria automobilística e 250 mil na indústria de autopeças).

Em 2011, quatro grandes empresas (General Motors, Ford, Volkswagen e Fiat) dominaram, com quase $75 \%$ do market-share doméstico: são todos os "first comers", o restante sendo principalmente "new-comers". O mercado interno tem sido um foco para a produção e vendas, mas com a concorrência cada vez maior, o mercado de exportação está ganhando importância, embora em declínio nos últimos anos, devido ao fortalecimento da moeda local (o Real). Oportunidades no mercado de exportação estão aumentando devido à demanda dos mercados emergentes e do Mercosul, um Tratado de Livre Comércio na Argentina, Brasil, Paraguai, Uruguai e recentemente com a Venezuela.

Nos últimos anos, vários novos arranjos organizacionais foram implementados na indústria automobilística brasileira. Entre eles estão o "consórcio modular" e "condomínios industriais", implicando na colaboração com fornecedores, em termos de percentagem de investimentos, locações de áreas, provisões de serviços e também mão de obra. Estes levaram a uma série de transformações, bem como a internacionalização da base de fornecedores em operação no Brasil, com um grande número de fusões, aquisições, alianças e encerramentos. Estes novos 
modelos são caracterizados por um alto grau de terceirização, contratos de longo prazo, codesign, trocas de ativos e informações específicas e dependência mútua geral (Salerno et al., 2009).

Essas estratégias geralmente implicam na delegação de responsabilidades aos fornecedores que assumem design e funções de produção, que por sua vez aumentam o seu poder dentro da cadeia de fornecimento. A literatura aponta para uma mudança da relação de competitividade tradicional e de relação cliente-fornecedor de curto prazo para parcerias estratégicas de colaboração de longo prazo. Em outras palavras, as empresas são incentivadas a abandonar a relação comprador-vendedor tradicionais em favor de uma relação mais estável e de colaboração com seus fornecedores.

O comércio de autopeças no Brasil tem apresentado um crescimento consistente nas últimas décadas, com vendas totais quase triplicando no período de vinte anos 1990-2011. Isso pode ser explicado pelos constantes investimentos neste setor, especialmente em meados de 1990. Além disso, a implementação do "Plano Real", em 1994, também foi importante, uma vez que a moeda local era indexada ao dólar dos EUA e controlava as altas taxas de inflação que assolaram o país e como resultado, incentivou o comércio inclusive automotivo. Com esta adoção, a moeda brasileira ficou mais forte permitindo que muitos consumidores dispusessem de carros novos, especialmente com importações de veículos mais baratos. Devido a isso, e como os efeitos do plano econômico foram consolidados, a importação de novas peças de automóvel cresceu. Em muitos anos, essas importações superaram o investimento orientado para o crescimento das exportações, gerando um déficit comercial de autopeças. Durante o período de 2007-2011, o saldo da balança comercial de auto peças do Brasil foi negativo (-4,6 milhões de dólares em 2011), embora, em 2006, foi positivo (2,1 milhões de dólares). Uma moeda forte, juntamente com elevados custos locais está levando a indústria de autopeças a sua desindustrialização.

\subsection{Políticas Industriais do Governo Brasileiro para a Indústria Automotiva}

Seis marcos na evolução da política do governo para o mercado automotivo brasileiro e da indústria, desde a sua criação na década de 1950, podem ser identificados. Cada um implicou numa significativa redefinição de produto local e estratégias de tecnologia para montadoras, atraindo novos players no mercado brasileiro (Figura 2). 
Figura 2: Correlação da Política Brasileira da Indústria Automobilística e a entrada de novos players no mercado.

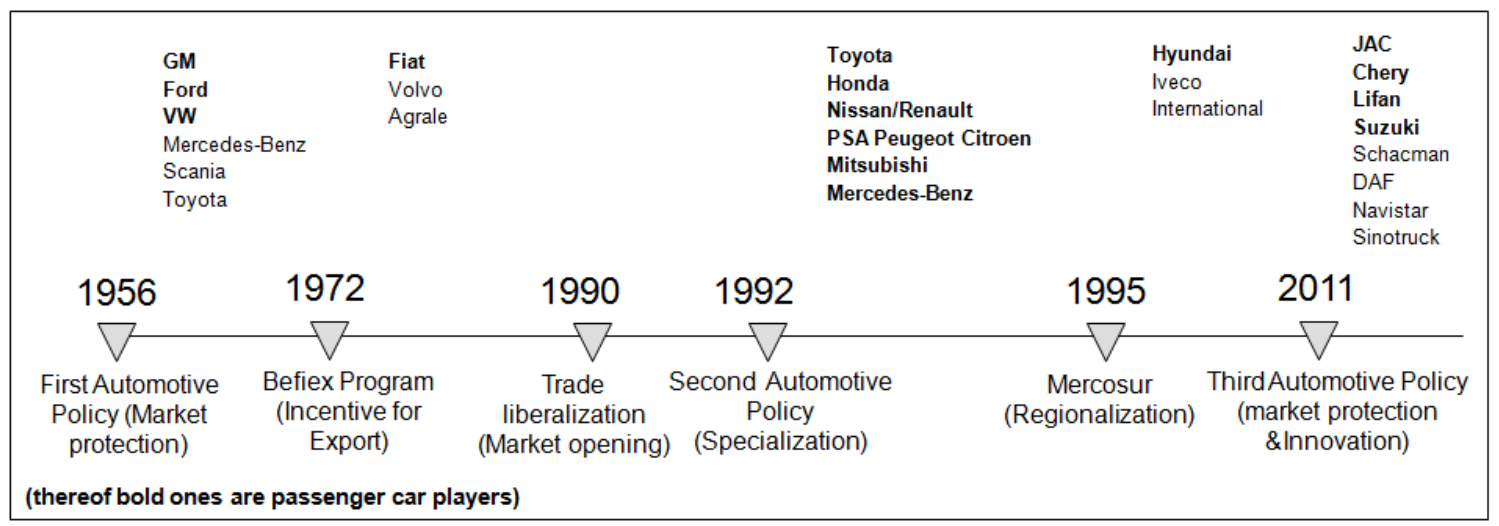

Fonte: Ibusuki et al (2012)

Com relação a mais recente Política Industrial Automotiva (INOVAR-AUTO), anunciada em agosto de 2011, pode ser considerado um avanço em termos de formulação de políticas industriais do país. O INOVAR-AUTO tem como foco o reforço da cadeia produtiva, que exige inovação e qualificação profissional. Foi estabelecido em duas ondas de requisitos:

- De 2011 à 2012: o conteúdo local de 65\% com base na receita, investimentos em $\mathrm{R} \& \mathrm{D}$ de $0,5 \%$ do faturamento e as etapas especificas de fabricação locais (6 de 11 etapas mínimas de fabricação) a fim de criar e fortalecer competências críticas para a economia e forçar a produção de automóveis e autopeças locais. Aos fabricantes que não atingirem estes requisitos será cobrado adicional de 30\% do IPI (Imposto de Produtos Industrializados);

- De 2013 à 2017: com base no adicional de 30\% do IPI, redução dos impostos calculados pelo valor das compras regionais (Mercosul) ajustado por um fator de 1,3 em 2013 e diminuindo para os anos seguintes até 1,0, em 2017; a redução do IPI adicional para as empresas que cumprirem requisitos mínimos de investimentos em R\&D e Engenharia (Tecnologia Industrial Básica) para o montante de 50\% do investimento limitado a $1 \%$ do IPI cada; a exigência de etapas de produção locais mínimos (estamparia, soldagem, pintura, injeção de plástico, montagem de motor, montagem da transmissão, direção e suspensão de componentes, montagem do sistema elétrico, sistema de freio e conjunto do eixo, montagem do quadro, montagem final, laboratório); exigência de etiquetagem dos veículos com relação ao consumo de combustível homologado pelo INMETRO (Instituto Nacional de Metrologia) e meta de $-12 \%$ de redução no consumo de combustível até 2017 com base em medições de 2012, com a redução de IPI adicional para a superação da meta (1\% do IPI para $-15,4 \%$ de redução no consumo de combustível e adicional de $1 \%$ do IPI para $-18,8 \%$ de redução no consumo de combustível).

Para habilitação das empresas no benefício de redução do IPI, a exigência de cumprir 2 de 3 etapas opcionais (tabela 1) e atender às etapas de fabricação mínimas assim como a meta de 
redução de consumo de combustível, com risco de multa em caso de não-realização reembolso retroativo de todos os impostos de IPI deduzidos.

Tabela 1: Requisitos para habilitação no INOVAR-AUTO (automóveis de passeio)

\begin{tabular}{|l|c|c|c|c|c|}
\hline Condições para a Redução de IPI & $\mathbf{2 0 1 3}$ & $\mathbf{2 0 1 4}$ & $\mathbf{2 0 1 5}$ & $\mathbf{2 0 1 6}$ & $\mathbf{2 0 1 7}$ \\
\hline $\begin{array}{l}\text { Faturamento Bruto investido em R\&D } \\
\text { (opcional) }\end{array}$ & $0.15 \%$ & $0.30 \%$ & $0.50 \%$ & $0.50 \%$ & $0.50 \%$ \\
\hline $\begin{array}{l}\text { Faturamento Bruto investido em } \\
\text { Engenharia (opcional) }\end{array}$ & $0.50 \%$ & $0.75 \%$ & $1.00 \%$ & $1.00 \%$ & $1.00 \%$ \\
\hline $\begin{array}{l}\text { Rotulagem veículos - \% dos modelos } \\
\text { (opcional) }\end{array}$ & $36 \%$ & $49 \%$ & $64 \%$ & $81 \%$ & $100 \%$ \\
\hline $\begin{array}{l}\text { Processos de Fabricação mínimos } \\
\text { (mandatório) }\end{array}$ & 8 & 9 & 9 & 10 & 10 \\
\hline $\begin{array}{l}\text { Redução de IPI com base na quantidade } \\
\text { de } \\
\text { seguintes fatores regionais ajustado pelo }\end{array}$ & 1.30 & 1.25 & 1.15 & 1.10 & 1.00 \\
\hline
\end{tabular}

Fonte: Governo Federal (2012)

\section{Base teórica para o estudo}

\subsection{Inovação Aberta (Open Innovation)}

As empresas organizam processos para a geração de inovação com o intuito de lançar novos produtos e serviços, desenvolver novos processos ou novas configurações organizacionais e atuar em novos mercados. Ao estudar o processo de inovação, autores como Clark e Wheelwright (1993) e Dodgson, Gann e Salter (2006) salientam que, durante muito tempo, esse processo foi desenvolvido com foco demasiado nos recursos internos, havendo pouca interação e baixo acesso ao conhecimento externo. Os primeiros estágios do processo de inovação tecnológica, alcançados até a década de 1980, foram realizados de maneira eminentemente interna à empresa para gerar o conhecimento, desenvolver o produto e comercializá-lo no mercado. Porém existe uma crescente complexidade tecnológica no desenvolvimento de novos produtos, o que vem motivando as empresas à necessidade de acesso a conhecimentos externos por meio de relacionamentos colaborativos com outros agentes. No início desta última década, Chesbrough (2003) denominou essa mudança de perspectiva com o termo "inovação aberta" em alternativa ao modelo dominante "inovação fechada", representando, obviamente, dois extremos de um contínuo. Para o autor, a abertura do modelo fechado de inovação é imperativa, sobretudo pelo aumento da velocidade de lançamentos de novos produtos, ocasionado pela crescente redução dos seus ciclos de vida. Ao abrir-se para o ambiente externo, a empresa poderá acessar relevantes conhecimentos para 
o processo de inovação. Em indústrias intensivas em conhecimento, as práticas de inovação colaborativa já ocorrem há algum tempo, como é o caso das indústrias de biotecnologia ou de produtos eletrônicos. Ainda são pouco conhecidas na literatura, no entanto, as práticas colaborativas de inovação em indústrias mais maduras, como no caso do desenvolvimento de produtos na indústria automotiva. A tradição dessa indústria está no desenvolvimento de produtos por meio de alto nível de internalização, em especial devido aos altos investimentos em ativos específicos na produção de componentes constituintes de um veículo (CLARK e FUJIMOTO, 1991). Em outros estudos, porém, Fujimoto e Takeishi (2001) demonstram que as empresas automotivas começaram a estabelecer parcerias para o desenvolvimento de tecnologias com seus fornecedores, dando os primeiros passos à abertura do processo de inovação. Evidências dessa perspectiva mais colaborativa de interação também podem ser encontradas no trabalho de Dyer e Nobeoka (2000) ao apresentar o sistema "Toyota" de relacionamento com sua rede de fornecedores.

\subsection{Aplicação do Lean Manufacturing na Inovação Aberta (Open Innovation)}

No Lean Manufacturing, discutimos questões dos 8 desperdícios tanto nos processos de manufatura, quanto em serviços (office), que são as atividades que não agregam valor como por exemplo, superprodução, espera, transporte, movimentação, processamento, retrabalho, produtos defeituosos, criatividade e esta última por sua vez não aproveitada pelos colaboradores especialistas nos processos pelo simples fato de que os gestores tem em mente que projetos devem ser executados pelos técnicos e os operadores devem apenas operar máquinas. Este é um paradigma que deve ser quebrado e os gestores não necessariamente precisam executar projetos de melhoria contínua do começo ao fim, mas sim atuarem como moderadores, facilitadores dos projetos "kaizen" delegando sim a possibilidade de um "especialista do processo" executar o projeto, pois na maioria das vezes são os especialistas que conhecem os "atalhos" para que tenhamos sucesso nos projetos (Womack, Jones 1998).

O estudo em questão analisou o modelo de Gestão Colaborativa de uma montadora de veículos junto a seus fornecedores através de um projeto de melhoria contínua desenvolvido por um time permanente de "kaizen" utilizando as ferramentas do "Lean Manufacturing" e replicando a vários outros fornecedores num modelo de inovação aberta.

Este projeto de melhoria contínua é denominado COSD - Cost Oriented Supplier Development, ou seja, é uma metodologia que visa capacitar a cadeia de fornecedores, envolvendo não só os fornecedores diretos (Tier 1), mas também muitas vezes os subfornecedores (Tier 2). Com o COSD, novos desafios foram lançados aos fornecedores, a geração de potenciais de redução de custos por meio da metodologia aplicada é baseada na utilização de três módulos essenciais, dos cinco módulos de atuação, sendo os 3 principais denominados TCR - Technical Complexity Reduction (adaptação dos produtos às exigências dos mercados, funcionalidade e atendimento à demanda da produção), CIP - Continuous Improvement Process (análise detalhada de todo processo produtivo e otimização dos processos desde a matéria-prima até a expedição) e o terceiro módulo CA - Cost Analysis 
(análise dos geradores de custos, definição das prioridades das medidas, avaliação de viabilidade das propostas e análise de preços de componentes comprados) e complementando os módulos de "Treinamento Lean Manufacturing" e "Logística" (este módulo visa analisar a logística inbound / outbound, questões de movimentações desnecessárias, fretes, pontos de distribuição e embalagens).

A geração de potenciais de redução de custos por meio da metodologia COSD contribui de forma significativa para o aumento da competitividade tanto para a montadora como seus fornecedores e a visão dos fornecedores que tiveram a oportunidade de participar de um projeto COSD é de que em um mercado tão competitivo cada vez mais se torna importante a utilização de novas parcerias, pois ambos buscam conjuntamente otimizar seus resultados, além disso, os fornecedores tem a oportunidade de replicar a metodologia e a sistemática do projeto COSD para outros clientes, fortalecendo ainda mais esta aliança.

O campo de atuação desta metodologia é imenso e não tem restrições em relação ao tipo de commodity, pois a essência do projeto está na metodologia de trabalho e não necessariamente a equipe do projeto, por parte da montadora, precisa ter especialização no segmento de atuação pelo fato de que os especialistas do projeto são os profissionais do fornecedor, além de ser uma metodologia permanente para a busca conjunta de redução de custos.

Neste estudo foram analisados todos os processos de fabricação de um determinado produto em ferro fundido, desde a matéria-prima até a expedição, sendo que a metodologia de mapeamento é voltada para as principais ferramentas do "Lean Manufacturing" que detectam atividades que não agregam valor ao produto além dos desperdícios de tempo, recursos e mão de obra utilizada. Neste caso foi detectada a necessidade de eliminação de um processo que não agregava valor ao produto, o de rebarbação na linha de partição do molde (Figura 3). Esta atividade tinha como objetivo extrair as rebarbas "cortantes" da peça, rebarbas estas que são geradas no momento da junção do material durante a fusão e preenchimento das cavidades do molde inferior e superior da peça. A necessidade de extração destas rebarbas são devido a vários fatores como exigência do cliente/desenho da peça, bem como qualidade visual da peça e também evitar acidentes no manuseio das mesmas durante os processos posteriores. 
Figura 3: Rebarbação Controlada

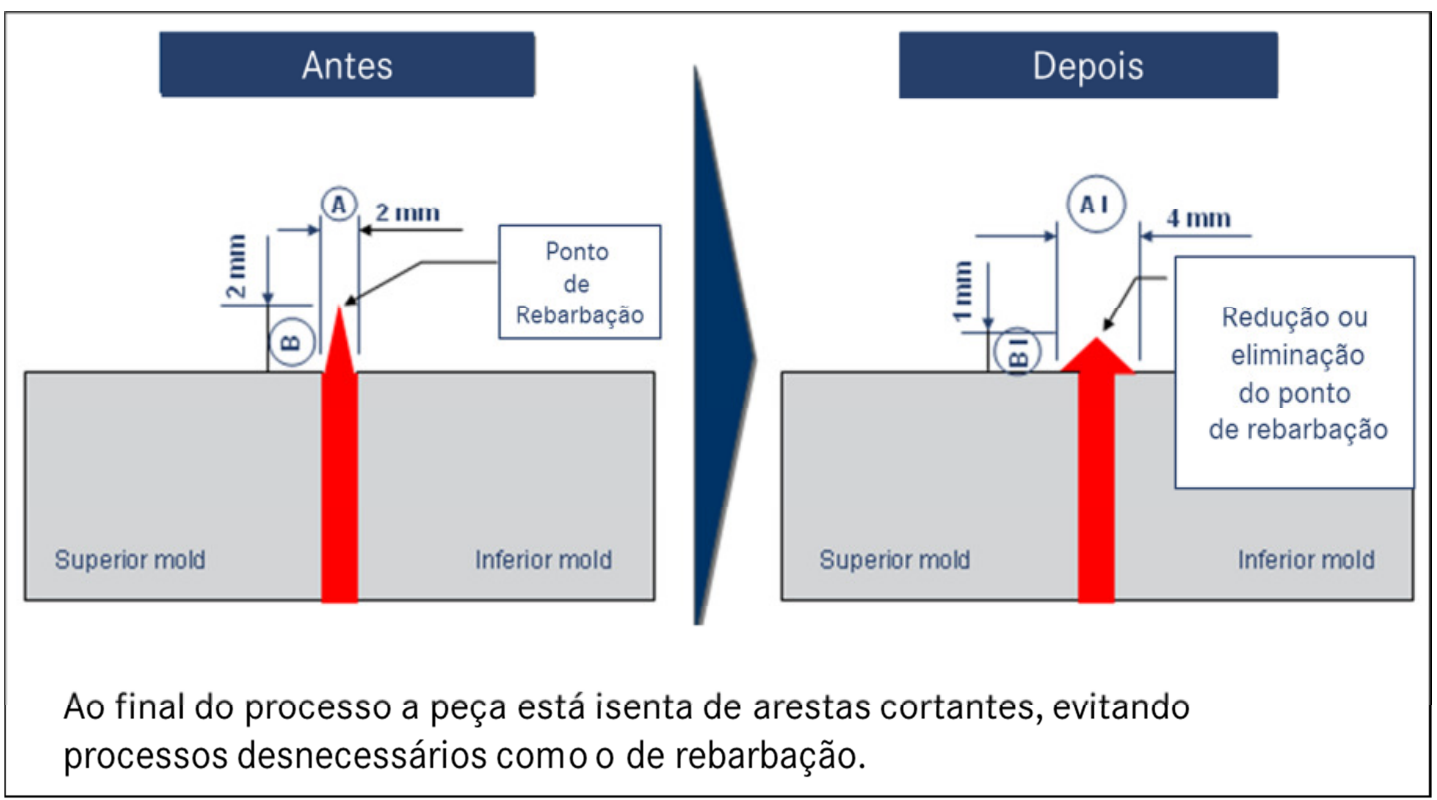

Durante o processo de mapeamento foram detectados vários pontos de melhoria nos 3 processos subsequentes de rebarbação da peça (rebolo, disco de corte, chicotinho) como desperdícios de movimentações entre outros, excesso de manuseios, transbordos, falta de ergonomia e riscos de segurança dos colaboradores além de comprometer os prazos de entrega devido ao lead time elevado.

Após a sessão de "Brainstorming", foram identificados vários cenários de melhoria no processo de rebarbação, porém a iniciativa mais relevante foi nomeada como "Rebarbação funcional ou controlada”. Esta iniciativa tinha como objetivo introduzir uma linha de partição por todo o contorno da peça. Esta linha de partição deveria conter uma altura e espessura prédeterminada pelas áreas multi-funcionais (qualidade e engenharia) e para que o conceito e a geometria da peça pudesse ser concebida, se fez necessária a adaptação no ferramental de fundição tanto nos moldes superiores quanto nos inferiores.

O investimento para tal modificação foi mínimo, pois a proposta poderia ser implementada no ferramental de uso vigente. Os principais ganhos desta iniciativa além das reduções de custos no produto foram: Aumento da segurança e ergonomia nos processos, redução do lead time de fabricação, racionalização de mão de obra, otimização de recursos e máquinas operatrizes, garantia de prazos de entrega. 


\section{Síntese da Análise e Conclusão}

A colaboração com fornecedores e universidades já é uma prática utilizada por outras empresas da indústria automotiva. Porém a transição de um modelo mais fechado, em que o foco recai demasiadamente no desenvolvimento a partir de recursos internos, para um modelo mais aberto, em que as interações com o ambiente externo passam a ser mais frequentes, sinalizam novos caminhos para a busca de competitividade na cadeia automotiva brasileira.

A nova política industrial (INOVAR-AUTO) aumenta as chances para o setor automotivo brasileiro contornar esta situação através de benefícios fiscais para a atividade de desenvolvimento de fornecedores onde até $50 \%$ das despesas com desenvolvimento de fornecedores de uma montadora poderá ser creditado através do desconto de IPI. O novo paradigma da relação montadora-fornecedor começa a se alterar de um ambiente de atrito para um ambiente de colaboração onde a busca de melhorias se dá através da parceria e de mútuo aprendizado.

O projeto desenvolvido num fornecedor de peças fundidas e replicado a outros cinco fornecedores trouxe um ganho médio através da redução do tempo de processamento da ordem de $30 \%$. Porém, o principal ganho deste projeto, foi a aproximação na relação de colaboração entre montadora e fornecedor que mostrou ganhos superiores ao antigo modelo de negociação e atrito onde o mais forte, no caso a montadora, cria um ambiente de pressão aos seus fornecedores para redução de custos porém muitas vezes gerando redução de margem de lucro, consequentemente perda na capacidade de investimento, perda de competitividade e perda de negócios para produtos importados.

Este caso de sucesso mostra claramente a importância do Lean manufacturing nos projetos e que a "Inovação tecnológica" não necessariamente precisa de grandes saltos como investimentos em novas máquinas, células de produção, etc e sim uma mudança cultural desde o gestor ao colaborador com uma visão simples e principalmente com quebras de paradigmas.

\section{REFERÊNCIAS}

[1] ANFAVEA, Annual Report of the Brazilian Automobile Industry, Sao Paulo, 2002, 2011.

[2] Arbix G., Zilbovicius M., De JK a FHC - a reinvenção dos carros, São Paulo: Scritta, 1997.

[3] CLARK, K. B; FUJIMOTO, T. Product development, performance strategy, organization and management in the world auto industry. Cambridge: Harvard Business Press, 1991.

[4] Clark K.B., Wheelwright S.C., Managing new product and process development - Text and cases. New York, NY: The Free Press, 1993. 
[5] CHESBROUGH, H. Open innovation: the new imperative for creating and profiting from technology. Boston, MA: Harvard Business School Publishing, 2003.

[6] DODGSON, M; GANN, D; SALTER, A. The role of technology in the shift towards open innovation: the case of Procter \& Gamble. R\&D Management, v. 36, n. 3, p. 333-346, 2006.

[7] DYER, J. H; NOBEOKA, K. Creating and managing a high-performance knowledgesharing network: the Toyota case. Strategic Management Journal, v. 21, n. 3, p. 345-367, 2000.

[8] Federal Government, Plano Brasil Maior: New Requirement, April 2012.

[9] FUJIMOTO, T; TAKEISHI, A. Automobiles: strategy-based lean production system. Tokyo: University of Tokyo, discussion papers, 2001.

[10] Ibusuki U., Kobayashi H., Kaminski P.C., Localization of product development based on competitive advantage of location and government policies: a case study of car makers in Brazil, Int. J. Automotive Technology and Management, Vol. 12, No. 2, pp. 172-196, 2012.

[11] Salerno M.S., Marx R., Zilbovicius M., Dias A.V.C., The Importance of Locally Commanded Design for the Consolidation of Local Supply Chain: the Concept of Design Headquarters, International Journal of Manufacturing Technology and Management, v.16, n.4, p.361-376, 2009.

[12] SHINGO, Shigeo. O Sistema Toyota de produção do ponto de vista da engenharia de produção. 2. ed Porto Alegre: Bookman, 1996.

[13] WOMACK, James P; JONES, Daniel T. A mentalidade enxuta nas empresas: elimine o desperdício e crie riqueza. ed Rio de Janeiro: Campus, 1998.

[14] Sindipecas, Brazilian Autoparts Industry Performance, 2011. 